\title{
Emissions from Buses with DDC 6V92 Engines Using Synthetic Diesel Fuel
}

\author{
Paul Norton and Keith Vertin \\ National Renewable Energy Laboratory (NREL) \\ Nigel N. Clark, Donald W. Lyons and Mridul Gautam \\ West Virginia University (WVU) \\ Stephen Goguen and James Eberhardt \\ U.S. Department of Energy (DOE)
}

Reprinted From: State of Alternative Fuels Technologies, 1999

(SP-1458)

International Spring Fuels \& 
SAE routinely stocks printed papers for a period of three years following date of publication. Direct your orders to SAE Customer Sales and Satisfaction Department.

Quantity reprint rates can be obtained from the Customer Sales and Satisfaction Department.

To request permission to reprint a technical paper or permission to use copyrighted SAE publications in other works, contact the SAE Publications Group.

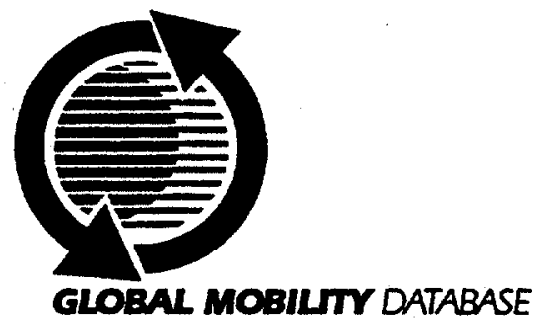

A// SAE papers, standards, and selected books are abstracted and indexed in the Global Mobility Database.

\section{ISSN 0148-7191}

Positions and opinions advanced in this paper are those of the author(s) and not necessarily those of SAE. The author is solely responsible for the content of the paper. A process is available by which discussions will be printed with the paper if it is published in SAE Transactions. For permission to publish this paper in full or in part, contact the SAE Publications Group.

Persons wishing to submit papers to be considered for presentation or publication through SAE should send the manuscript or a 300 word abstract of a proposed manuscript to: Secretary, Engineering Meetings Board, SAE. 


\title{
Emissions from Buses with DDC 6V92 Engines Using Synthetic Diesel Fuel
}

\author{
Paul Norton and Keith Vertin \\ National Renewable Energy Laboratory (NREL) \\ Nigel N. Clark, Donald W. Lyons and Mridul Gautam \\ West Virginia University (WVU) \\ Stephen Goguen and James Eberhardt \\ U.S. Department of Energy (DOE)
}

\begin{abstract}
Synthetic diesel fuel can be made from a variety of feedstocks, including coal, natural gas and biomass. Synthetic diesel fuels can have very low sulfur and aromatic content, and excellent autoignition maracteristics. Moreover, synthetic diesel fuels may also economically competitive with California diesel fuel if roduced in large volumes.
\end{abstract}

Previous engine laboratory and field tests using a heavyduty chassis dynamometer indicate that synthetic diesel fuel made using the Fischer-Tropsch (F-T) catalytic conversion process is a promising alternative fuel because it can be used in unmodified diesel engines, and can reduce exhaust emissions substantially.

The objective of this study was a preliminary assessment of the emissions from older model transit operated on Mossgas synthetic diesel fuel. The study compared emissions from transit buses operating on Federal no. 2 Diesel fuel, Mossgas synthetic diesel (MGSD), and a $50 / 50$ blend of the two fuels. The buses were equipped with unmodified Detroit Diesel 6V92 2-stroke diesel engines. Six 40-foot buses were tested. Three of the buses had recently rebuilt engines and were equipped with an oxidation catalytic converter. Vehicle emissions measurements were performed using West Virginia University's unique transportable chassis dynamometer. The emissions were measured over the Central Business District (CBD) driving cycle.
The buses performed well on both neat and blended MGSD fuel. Three buses without catalytic converters were tested. Compared to their emissions when operating on Federal no. 2 diesel fuel, these buses emitted an average of $5 \%$ lower oxides of nitrogen (NOX) and $20 \%$ lower particulate matter (PM) when operating on neat MGSD fuel. Catalyst equipped buses emitted an average of $8 \%$ lower NOx and $31 \%$ lower PM when operating on MGSD than when operating on Federal no. 2 diesel fuel

\section{INTRODUCTION}

The Energy Policy Act of 1992 (EPACT) was enacted to stimulate the research, development, and accelerated introduction of alternative fuel technologies in the United States. The objective of EPACT is to reduce the nation's dependence on imported petroleum by pursuing renewable and domestically produced energy resources. Under EPACT, DOE has established programs to promote energy diversity and the displacement of crude oil-based motor fuels.

"Gas-to-liquids" (GTL) process technology is one promising approach for achieving energy diversity [1-7]. A brief history of the Fischer-Tropsch GTL synthetic diesel process was given in a previous paper [8]. There has been heightened interest in GTL technology in recent years, as researchers and industrial firms are demonstrating favorable production economics. GTL fuel and chemical plants are emerging in developing countries. GTL pilot plants are also being developed for remote and off-shore applications to liberate remote and stranded natural gas reserves. F-T and other synthetic diesel fuels may be economically competitive with low aromatic California diesel fuel if produced in large volumes. For a 
commercial-scale plant, synthetic fuel price estimates range from $\$ 20$ to $\$ 25$ per barrel of product $[2,5-7]$.

Fischer-Tropsch synthetic diesel fuel is typically synthesized using a three-step procedure [2-6]. First a synthesis gas is produced from the feedstock, F-T catalysis is then used to convert this synthesis gas into liquid hydrocarbons, and finally the resulting synthetic crude is upgraded using standard hydrotreating and isomerization processes and fractionated into middle distillate fuels. This process can be used to create a variety of fuel properties depending on the process technology and streams being blended. Generally, synthetic diesel fuels have favorable characteristics for use in compression ignition engines including:

- Liquid phase at ambient conditions

- Miscible in conventional petroleum-derived diesel

- Good autoignition characteristics (cetane number of 50-75 typically)

- Low sulfur (typically less than $10 \mathrm{ppm}$ )

- Low aromatics (less than 3 vol\% possible)

- Energy density comparable to conventional diesel

- Fuel tank flammability similar to conventional diesel

- Suitable for use in unmodified diesel engines

- Transportable as a liquid in existing petroleum infrastructure.

Due in part to the success of previous engine and chassis based testing [9-12], synthetic diesel is being considered as a candidate fuel for the DOE/NREL Alternative Fuel Truck and Bus Evaluation Projects [13].

\section{TEST FUELS}

Three test fuels were used for the bus tests:

- Federal (49-state) no. 2 diesel fuel

- $100 \%$ Mossgas synthetic diesel with fuel lubricity additive

- 50:50\% Mossgas synthetic diesel:Federal no. 2 diesel with fuel lubricity additive

The synthetic diesel fuel for this study was produced using the Mossgas conversion of olefins to distillate ("COD") process. Mossgas produces a range of automotive fuel products and chemicals using a natural gas feedstock obtained by pipeline from their off-shore production platform in Mossel Bay, South Africa. The natural gas is reformed to synthesis gas consisting of hydrogen and carbon monoxide. The synthesis gas is chemically converted using high temperature Fischer-Tropsch catalysis to produce olefins and automotive fuel components for commercial markets.

The light olefins that remain from the Fischer-Tropsch conversion, such as propene, butene, pentene and hexene, were used to synthesize the test fuel used in this study. These light olefins were catalytically oligomerized over a zeolite catalyst to form gasoline and distillate. The resulting product was then hydrotreated. Mossgas uses the COD process to produce commercial specialty f and blendstocks.

The properties of the Mossgas synthetic diesel fuel and the Federal no. 2 diesel fuel used in this study are shown in Table 1. The Mossgas fuel had no detectable sulfur, and a cetane number of about 50 . The aromatic content was $10 \%$ by volume, which is higher than that of a typical Fischer-Tropsch diesel. The cold flow properties of the Mossgas fuel were excellent with a pour point and cloud point below -60 degrees Celsius. A commercially available lubricity improver (Paradyne 655 at $200 \mathrm{ppm}$ treat rate) was added to meet acceptable lubricity levels.

The Federal no. 2 diesel used in the study had a relatively low sulfur content of $0.02 \%$ by weight. This is much lower than the standard of $0.05 \%$ and lower than the $0.03 \%$ to $0.035 \%$ sulfur content typically found in Federal diesel.

\section{VEHICLE TESTING}

TEST VEHICLES - The buses used for the testing were loaned to the project by the Port Authority of Allegheny County ("PaTransit"). They were removed from revenue service in Pittsburgh, PA for the emissions measurements. The 40-foot buses were 1991 model year made by $O$ Bus Industries and equipped with 1991 model year D Diesel Corporation (DDC) 6V92 two-stroke diesel engines? One of the test buses is shown in Figure 1.

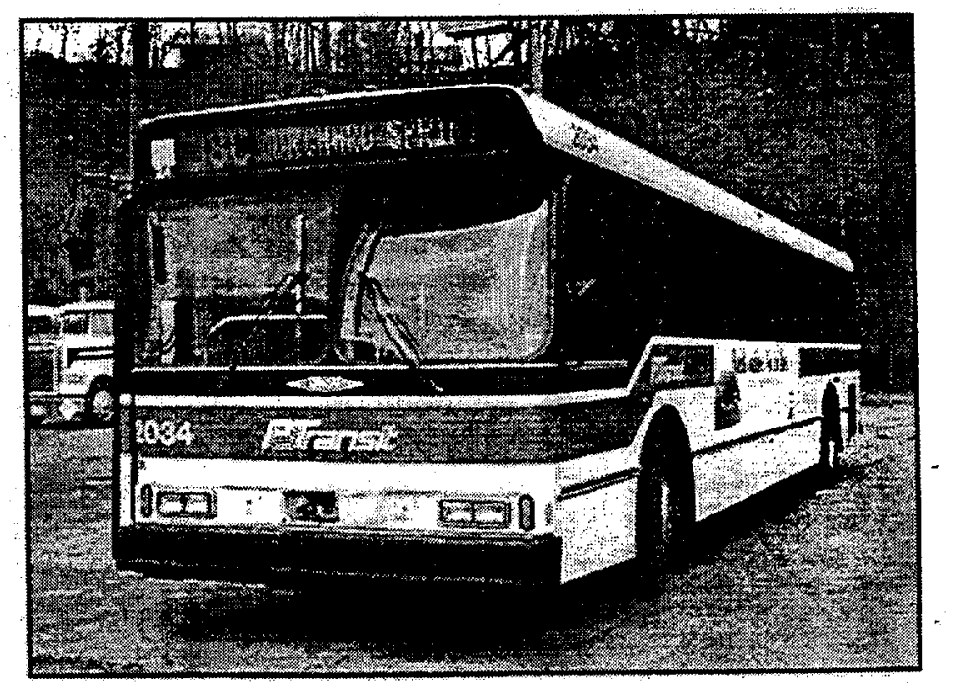

Figure 1: One of the Pittsburgh transit buses used for the emissions measurements. 
Table 1: Test Fuel Properties

\begin{tabular}{|c|c|c|c|c|c|}
\hline Analysis & ASTM & Units & $\begin{array}{c}\text { 100\% MGSD } \\
\text { (Mossgas Data) } \\
\text { [14] }\end{array}$ & $\begin{array}{l}\text { 100\% MGSD } \\
\text { (SwRI Data) } \\
\text { [15] }\end{array}$ & $\begin{array}{c}\text { Federal } \\
\text { Diesel Fuel } \\
\text { [16] }\end{array}$ \\
\hline Flash Point & D93 & ${ }^{\circ} \mathrm{C}$ & 100 & 97 & \\
\hline Cloud Point & D2550 & ${ }^{\circ} \mathrm{C}$ & & $<-60$ & \\
\hline Water content & $\overline{D 1744}$ & vol\% & 0.01 & & \\
\hline Sediment by extraction & D473 & mass $\%$ & $<0.01$ & & \\
\hline Water and Sediment & D1796 & vol\% & & 0 & \\
\hline Carbon Residue on $10 \%$ residue & D4530 & $w t \%$ & 0.09 & & \\
\hline $\begin{array}{l}\text { Carbon Residue on } 10 \% \text { distillation } \\
\text { residue }\end{array}$ & D524 & $\%$ & & 0.1 & \\
\hline Ash & D482 & $w t \%$ & $<0.01$ & & \\
\hline $\begin{array}{l}\text { Distillation } \\
\text { IBP } \\
10 \% \\
50 \% \\
90 \% \\
\text { FBP }\end{array}$ & D86 & ${ }^{\circ} \mathrm{C}$ & $\begin{array}{l}321.1 \\
360.8\end{array}$ & $\begin{array}{l}229.9 \\
235.3 \\
254.7 \\
323.7 \\
361.2\end{array}$ & $\begin{array}{l}188 \\
212 \\
256 \\
307 \\
331\end{array}$ \\
\hline Kinematic Viscosity & D445 & CSt@40ㄷ & 2.974 & 2.98 & \\
\hline Sulfur & D2622 & mass\% & $<0.001$ & & \\
\hline Sulfur & D5453 & $\mathrm{ppm}$ & & $<5$ & \\
\hline Sulfur & D4294 & $w t \%$ & & & 0.02 \\
\hline Corrosion, $100^{\circ} \mathrm{C}$ for 3 hours & D130 & Rating & $1 \mathrm{~A}$ & & \\
\hline Cetane Number & D613 & & 51.4 & 48.9 & \\
\hline Cetane Index & D4737 & & & & 48.7 \\
\hline Density @ 20 $\mathrm{C}$ & $\begin{array}{l}040521 \\
\text { D1298 }\end{array}$ & kg/l & 0.8007 & 0.8042 & \\
\hline API Gravity @ $15.6^{\circ} \mathrm{C}$ & D287 & ${ }^{\circ} \mathrm{API}$ & & 44.0 & 37.4 \\
\hline Cold Filter Plugging Point & IP309 & ${ }^{\circ} \mathrm{C}$ & $<-35$ & & \\
\hline Pour Point & D97 & ${ }^{\circ} \mathrm{C}$ & & $<-60$ & \\
\hline $\begin{array}{l}\text { SFC Aromatics } \\
\text { Total Aromatics } \\
\text { PNA }\end{array}$ & D5186 & mass $\%$ & & $\begin{array}{l}9.18 \\
0.21\end{array}$ & \\
\hline $\begin{array}{l}\text { FIA } \\
\text { Aromatic } \\
\text { Olefins } \\
\text { Saturate }\end{array}$ & D1319 & vol\% & & & $\begin{array}{c}24.7 \\
1.5 \\
73.8\end{array}$ \\
\hline Aromatics & IP391 & vol\% & 10.1 & & \\
\hline $\begin{array}{l}\text { Gum Content } \\
\text { Unwashed } \\
\text { Washed }\end{array}$ & D381 & $\mathrm{mg} / 100 \mathrm{ml}$ & & $\begin{array}{l}8.8 \\
0.4\end{array}$ & \\
\hline $\begin{array}{l}\text { Lubricity SLBOCLE } \\
\text { Neat Fuel } \\
\text { With Paradyne additive }\end{array}$ & D6078 & grams & & $\begin{array}{l}1950 \\
3800\end{array}$ & \\
\hline $\begin{array}{l}\text { Lubricity HFRR } \\
\text { Neat Fuel } \\
\text { With Paradyne additive }\end{array}$ & D6079 & micron & & $\begin{array}{l}600 \\
255\end{array}$ & \\
\hline Oxidation Stability & D2274 & $\mathrm{mg} / 100 \mathrm{ml}$ & 0.3 & & \\
\hline $\begin{array}{l}\text { Carbon/Hydrogen } \\
\text { Carbon } \\
\text { Hydrogen } \\
\text { Nitrogen } \\
\text { Residual } \\
\text { Oxygen (by diff) } \\
\end{array}$ & D5291 & mass $\%$ & & $\begin{array}{r}83.98 \\
14.43 \\
\\
1.59\end{array}$ & $\begin{array}{l}86.11 \\
13.37 \\
<0.03\end{array}$ \\
\hline $\begin{array}{l}\text { Heat of Combustion } \\
\text { Gross } \\
\text { Net }\end{array}$ & $\mathrm{D} 240$ & Btu/gal & & $\begin{array}{l}134,712 \\
125,878\end{array}$ & $\begin{array}{l}137,609 \\
129,147\end{array}$ \\
\hline
\end{tabular}


The DDC 6V92 is a 2-stroke, vee-configuration, 6 cylinder, 9.05 liter, turbocharged and aftercooled diesel engine with electronic unit fuel injectors. The Pittsburgh bus engines were rated to 253 horsepower (at $2100 \mathrm{rpm}$ ) and $880 \mathrm{ft}-\mathrm{lb}$ of torque (at $1200 \mathrm{rpm}$ ).

Three of the six buses used in this study used engines with high mileage accumulation (typically over 350,000 miles) and were not equipped with exhaust gas aftertreatment. The other three buses had engines that were recently rebuilt according to the Environmental Protection Agency's Urban Bus Retrofit/Rebuild Program and were fitted with an oxidation catalytic converter manufactured by Engine Control Systems Ltd. Bus number 2029 was tested early in the study without a catalyst. It was then fitted with a rebuilt engine and a catalytic converter and retested. The test buses were not modified in any way for the Mossgas synthetic diesel fuel.

CHASSIS EMISSIONS TESTING - West Virginia University (WVU) measured emissions for this study using one of its transportable emissions laboratories located at the WWU home site in Morgantown, WW. The transportable laboratory consists of a heavy-duty chassis dynamometer and an emissions measurement facility. Design details of the laboratory and previous emissions measurements using the laboratory have been presented in several previous reports [17-25].

Chassis Dynamometer - The dynamometer equipment is mounted on a fifth wheel semi-trailer for portability. Upon arriving at the test site, the wheels of the trailer are removed and the trailer is lowered to the ground. The test vehicle is driven onto two sets of free running rollers mounted in the trailer bed. Power is transferred from the test vehicle to the dynamometer through hub adapters that are bolted to the drive wheels. The inertia weight of the bus is simulated by a set of flywheels. The road load is applied to the test vehicle using air-cooled eddy current power absorbers. Figure 2 shows one of the test buses mounted on the dynamometer.

Emissions Measurements - The emissions measurement

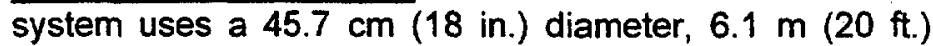
long exhaust dilution tunnel mounted atop the box trailer that houses the emissions measuring equipment. Two fans and critical flow venturis control the flow rate in the dilution tunnel.

Carbon monoxide (CO), carbon dioxide $\left(\mathrm{CO}_{2}\right)$, oxides of nitrogen $\left(\mathrm{NO}_{\mathrm{x}}\right)$, and total hydrocarbons (THC) are measured continuously throughout the test. Particulate matter (PM) is captured on a filter and weighed. Bag samples are collected and analyzed for background correction.

Test Method - The buses were tested using the Central Business District (CBD) driving cycle described in SAE Recommended Practice J1376. The CBD driving cycle was developed by the Federal Transit Administration to represent the operation of a transit bus in a downtown business district. The cycle, shown in Figure 3, consists of

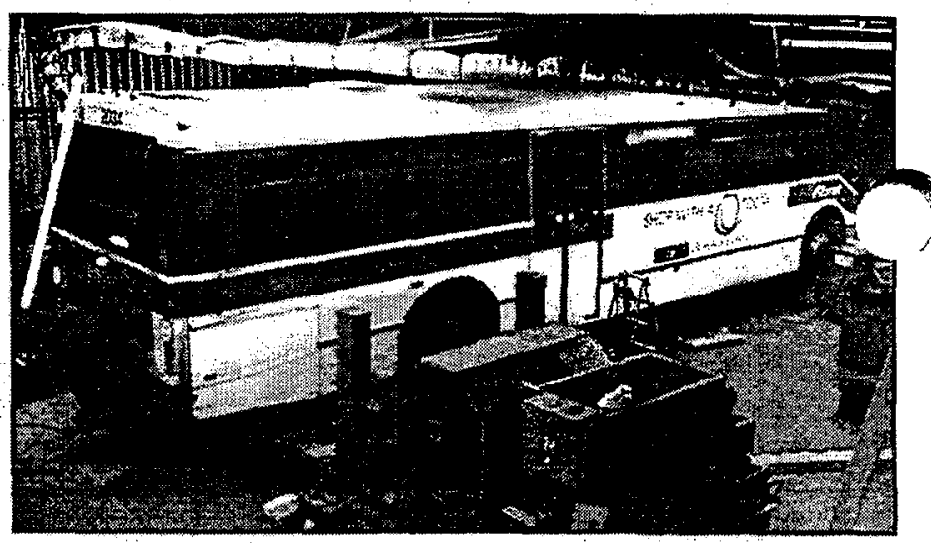

Figure 2: One of the PaTransit buses on the WVU transportable chassis dynamometer

fourteen identical acceleration, cruise, and deceleration cycles. A short idle time was added before and after the vehicle activity to aid data gathering in the light of sampling delay times [26]. The cruise sections occur at $32 \mathrm{~km} / \mathrm{hr}$ (20 mph). Transit bus emissions measurements using this driving cycle have been reported in many previous papers [for example, 22, 27-29].

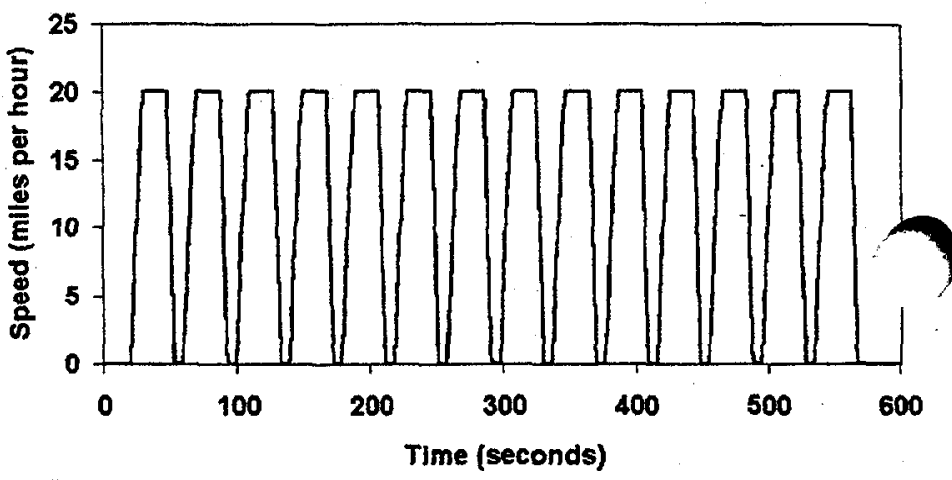

Figure 3: The Central Business District (CBD) driving cycle.

Tests Performed - Three buses with rebuilt engines and equipped with catalytic converters and three buses without catalytic converters were tested. The emissions from each bus were measured while the bus operated on each of the three test fuels. Between measurements with different fuels, the bus' fuel system was emptied and flushed with the new fuel type. The emission tests performed are summarized in Table 2.

Table 2: Summary of Emissions Tests Performed

\begin{tabular}{|l|l|c|}
\hline & \multicolumn{1}{|c|}{ Fuel } & $\begin{array}{c}\text { Number of } \\
\text { Tests }\end{array}$ \\
\hline \multirow{2}{*}{$\begin{array}{l}\text { Buses with } \\
\text { rebuilt engines and } \\
\text { catalytic converters }\end{array}$} & No. 2 Diesel & 3 \\
\cline { 2 - 3 } & $100 \%$ MGSD & 3 \\
\hline \multirow{2}{*}{$\begin{array}{l}\text { Buses without } \\
\text { catalytic converters }\end{array}$} & No\% MGSD & 3 \\
\cline { 2 - 3 } & $100 \%$ MGSD & 3 \\
\cline { 2 - 3 } & $50 \%$ MGSD & 3 \\
\hline \multicolumn{2}{|l}{} & Total $=18$ \\
\hline
\end{tabular}




\section{RESULTS}

Drivers could not detect a performance difference between buses operating on the Mossgas synthetic diesel and the

Federal no. 2 diesel fuel over the CBD driving cycle. The verage emissions results are summarized in Table 3 . At least three measurements were taken and averaged for each result presented in the table.

EFFECT OF TEST FUEL - Three buses equipped with rebuilt engines and catalytic converters were tested on the three test fuels. The results of these tests are shown in the bar charts of Figure 4. Each chart shows results for each bus and the average of all three buses. Substituting $100 \%$ MGSD fuel in place of no. 2 diesel fuel led to lower average levels of all four emissions measured. $\mathrm{NO}_{x}$ was reduced by an average of $8 \%$, PM was reduced by an average of $31 \%$, CO was reduced by an average of $49 \%$, and $\mathrm{HC}$ was reduced by an average of $35 \%$. The average $\mathrm{NO}_{\mathrm{x}}$ reduction with a 50:50 blend of no. $i$ diesel and MGSD was substantially more than half of the reduction with $100 \%$ MGSD fuel. The PM reduction with the blend was approximately half of the reduction measured with $100 \%$ MGSD fuel.

With the exception of the hydrocarbon emissions from bus 2029 , all buses followed the same trend of progressively decreasing emissions with $50 \%$ and $100 \%$ Mossgas synthetic diesel.

Table 3: Average emissions (in grams per mile) and fuel mileage from buses tested on federal No. 2 diesel, Mossgas synthetic diesel (MGSD), and a 50:50 blend of the two fuels.

\begin{tabular}{|c|c|c|c|c|c|c|c|c|c|}
\hline & Fuel & \begin{tabular}{|c|} 
Bus \\
Number
\end{tabular} & $\mathrm{CO}$ & $\mathrm{NO}_{x}$ & $\mathrm{HC}$ & PM & $\mathrm{CO}_{2}$ & MPG* & Btu/mile \\
\hline \multirow{12}{*}{$\begin{array}{l}\text { Buses with } \\
\text { rebuilt engines and } \\
\text { catalytic converters }\end{array}$} & No. 2 Diesel & 2025 & 1.96 & 34.51 & 0.75 & 1.23 & 4355 & 2.33 & 55713 \\
\hline & No. 2 Diesel & 2029 & 1.07 & 26.91 & 0.39 & 1.89 & 4458 & 2.28 & 56995 \\
\hline & No. 2 Diesel & 2048 & 2.11 & 29.71 & 0.75 & 1.12 & 3451 & 2.94 & 44159 \\
\hline & Averages: & & $\overline{1.71}$ & 30.38 & $\overline{0.63}$ & 1.41 & 4088 & 2.52 & 52289 \\
\hline & $50 \%$ MGSD & 2025 & 1.34 & 31.93 & $\overline{0.54}$ & 1.14 & 4360 & 2.20 & 57589 \\
\hline & $50 \%$ MGSD & 2029 & 0.81 & 26.40 & 0.40 & 1.59 & 4346 & 2.21 & 57391 \\
\hline & $50 \%$ MGSD & 2048 & 1.51 & 27.69 & 0.59 & 0.83 & 3381 & 2.84 & 44672 \\
\hline & Averages: & & 1.22 & 28.67 & $\overline{0.51}$ & 1.19 & 4029 & 2.42 & 53217 \\
\hline & $100 \%$ MGSD & 2025 & 1.02 & 31.37 & $\overline{0.44}$ & 1.01 & 4206 & 2.19 & 56272 \\
\hline & $100 \%$ MGSD & 2029 & 0.75 & 26.10 & 0.29 & 1.16 & 4181 & 2.21 & 55928 \\
\hline & $100 \%$ MGSD & 2048 & 0.82 & 26.53 & 0.49 & 0.76 & 3338 & 2.77 & 44659 \\
\hline & Averages: & & 0.87 & 28.00 & 0.41 & 0.97 & 3908 & 2.39 & 52286 \\
\hline \multirow{12}{*}{$\begin{array}{l}\text { Buses without } \\
\text { catalytic converters }\end{array}$} & No. 2 Diesel & 2029 & 11.73 & $\overline{35.85}$ & 1.82 & 1.79 & $4 \overline{4328}$ & 2.34 & 55598 \\
\hline & No. 2 Diesel & 2030 & 6.65 & 34.88 & 2.11 & 1.18 & 4149 & 2.44 & 53221 \\
\hline & No. 2 Diesel & 2034 & 40.42 & 26.26 & 1.31 & 9.03 & 4900 & 2.05 & 63468 \\
\hline & Averages: & & 19.60 & 32.33 & 1.75 & 4.00 & 4459 & 2.28 & 57429 \\
\hline & $50 \%$ MGSD & 2029 & 10.33 & 32.23 & 1.88 & 1.52 & 4348 & 2.20 & 57601 \\
\hline & $50 \%$ MGSD & 2030 & 6.26 & 33.93 & 2.03 & 1.13 & 4099 & 2.34 & 54244 \\
\hline & $50 \%$ MGSD & 2034 & 37.91 & 26.02 & 0.99 & 8.61 & 4704 & 2.02 & 62887 \\
\hline & Averages: & & 18.16 & 30.72 & 1.63 & $\overline{3.75}$ & 4383 & 2.18 & 58274 \\
\hline & $100 \%$ MGSD & 2029 & 11.02 & 33.37 & 1.72 & 1.34 & 4392 & 2.09 & 58963 \\
\hline & $100 \%$ MGSD & 2030 & 5.73 & 32.92 & 1.75 & 1.16 & 4133 & 2.23 & 55391 \\
\hline & $100 \%$ MGSD & 2034 & 26.52 & 25.64 & 0.72 & 7.07 & 4639 & 1.97 & 62596 \\
\hline & Averages: & & 14.42 & 30.64 & 1.40 & 3.19 & 4388 & 2.10 & 58984 \\
\hline
\end{tabular}

* Miles per liquid gallon (not corrected for energy content) 

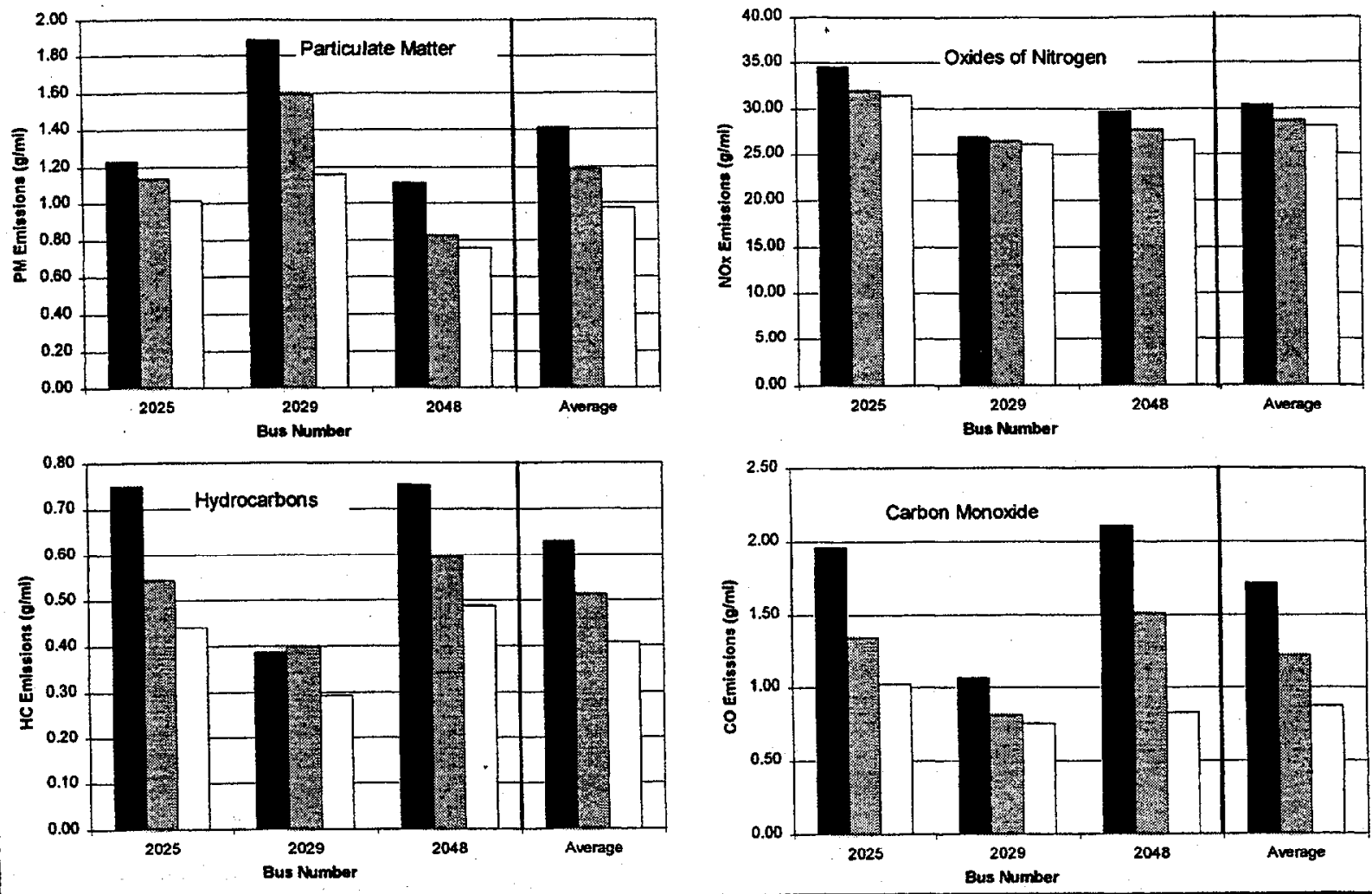

No. 2 Diesel

50\% MGSD

$100 \%$ MGSD

Figure 4: Emissions results from buses with rebuilt engines and catalytic converters
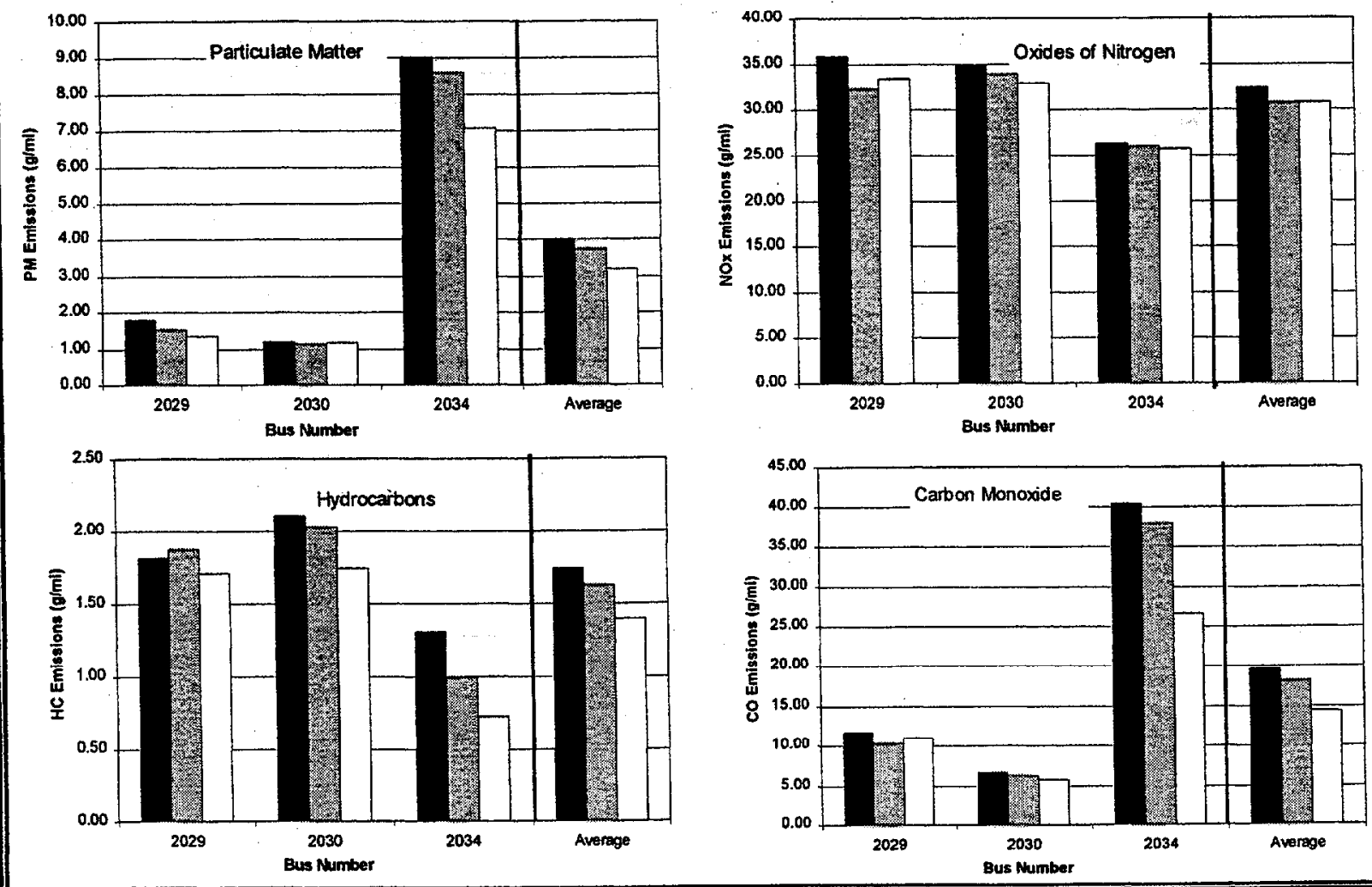

No. 2 Diesel

50\% MGSD

$\square 100 \%$ MGSD

Figure 5: Emissions results from buses without catalytic converters 
Three buses with high mileage engines and no catalytic converters were also tested. The results of these tests are shown in the bar charts of Figure 5 . Substituting $100 \%$ Mossgas synthetic diesel fuel in place of Federal no. 2 iesel fuel in these buses also led to lower average levels of all four emissions measured. $\mathrm{NO}_{x}$ was reduced by an average of $5 \%, \mathrm{PM}$ was reduced by an average of $20 \%$, $\mathrm{CO}$ was reduced by an average of $26 \%$, and $\mathrm{HC}$ was reduced by an average of $20 \%$. In this case, The average $\mathrm{NO}_{\mathrm{x}}$ reduction with a 50:50 blend of no. 2 diesel and MGSD was nearly identical to the reduction with $100 \%$ MGSD. This result agrees with an earlier study by the authors on class 8 trucks using Shell Middle Distillate F-T fuel [8]. In contrast, the PM reduction with the blend was only about a quarter of the reduction measured with $100 \%$

- MGSD fuel.

Bus number 2034 had dramatically higher PM and CO emissions and somewhat lower NOx and HC emissions than buses 2029 and 2030. Although buses 2029 and 2030 had similar fuel consumption (within about 4\%), the fuel consumption of bus 2034 on Federal no. 2 diesel was somewhat higher (about $16 \%$ higher than the average of buses 2029 and 2030). The higher fuel consumption and lower NOx indicates that the injection timing in bus 2034 may be retarded relative to manufacturer specifications. Note that much of the average PM reduction with MGSD in this set of buses is due to the large reduction in PM from bus 2034.

Vhen tested on 50\% MGSD, the emissions trends of bus number 2029 (without a catalyst) were different than the other two non-catalyst buses for NOx, HC, and CO. These trends can be seen clearly in Figure 5 . The cause of this anomaly is unknown.

EFFECT OF REBUILT ENGINES AND CATALYST - The average emissions from buses with rebuilt engines and catalytic converters are compared to emissions from buses with older engines and no catalytic converters in Figures 6 and 7 . The buses with rebuilt engines and catalysts had dramatically lower $\mathrm{CO}, \mathrm{HC}$ and PM emissions than those with older engines and no catalyst. Most of this reduction is likely due to the oxidizing effect of the catalyst on $\mathrm{CO}$, $\mathrm{HC}$, and the soluble organic fraction of the PM emissions.

Also apparent from Figures 6 and 7 is that NOx emissions were reduced somewhat in the buses with rebuilt engines and catalytic converters. The NOx reduction cannot be attributed to the catalyst. The emission reductions from buses with rebuilt engines and catalysts followed the same trends in all buses with both MGSD and Federal no. 2 diesel.

Continuous gaseous emission rates were measured during the tests. Although not directly relevant to the comparison of fuels, an interesting trend in the continuous data varrants mentioning. Buses with oxidation catalytic converters had decreasing $\mathrm{HC}$ and $\mathrm{CO}$ emissions over the course of the CBD test cycle. Typical continuous $\mathrm{HC}$ and $\mathrm{CO}$ for a catalyst-equipped bus are shown in Figures 8

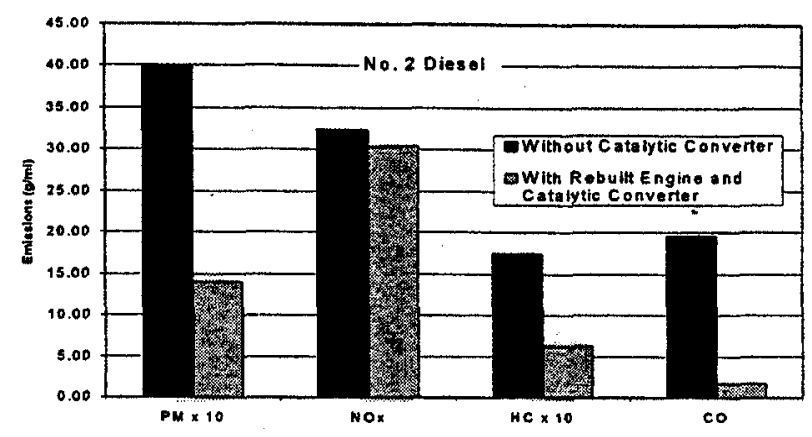

Figure 6: Average emissions results from buses with rebuilt engines and catalytic converters compared to buses without catalytic converters while operating on no. 2 diesel fuel.

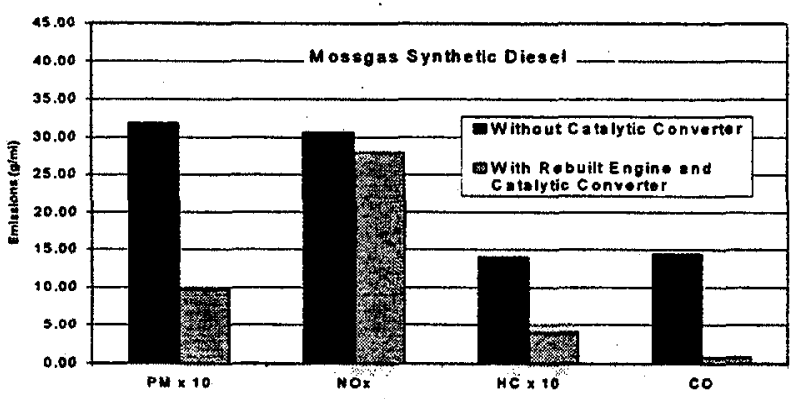

Figure 7: Average emissions results from buses with rebuilt engines and catalytic converters compared to buses with out catalytic converters while operating on Mossgas synthetic diesel fuel.

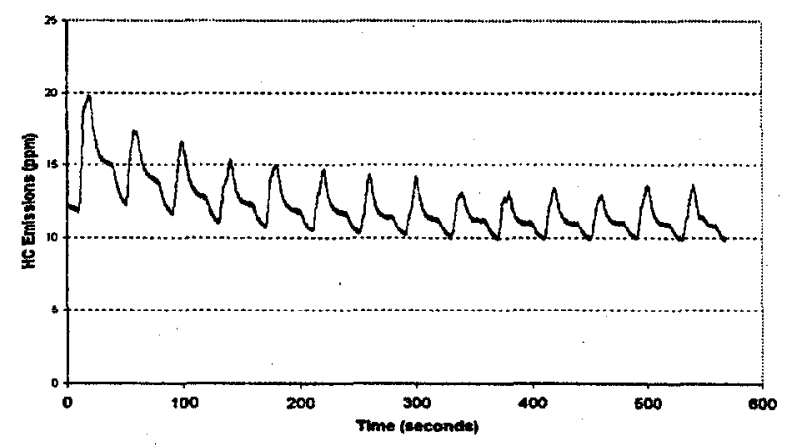

Figure 8: Continuous $\mathrm{HC}$ emissions over the CBD cycle from a bus with rebuilt engine and catalytic converter.

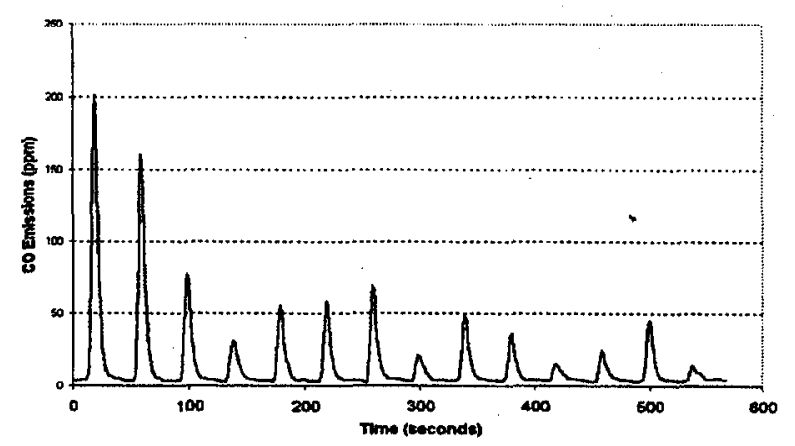

Figure 9: Continuous $\mathrm{CO}$ emissions over the CBD cycle from a bus with rebuilt engine and catalytic converter. 
and 9. This trend was not observed in buses without catalysts.

Figures 8 and 9 clearly illustrate that the $\mathrm{HC}$ and $\mathrm{CO}$ drop progressively over the cycle. The WWU protocol for the $\mathrm{CBD}$ test cycle includes three additional peaks of the CBD just prior to the actual test data shown here, so the catalyst has already seen some exhaust warming. These results indicate that a test facility that did not employ the warm-up ramps would see higher average $\mathrm{HC}$ and $\mathrm{CO}$ emissions than measured in this study. This suggests a need for more precisely defined heavy duty vehicle chassis testing protocols to avoid measurement differences between facilities.

FUEL CONSUMPTION - For each of the buses tested, the fuel consumption (in Btu/mile) was not strongly affected by the fuel type. No more than a $3 \%$ deviation from the average fuel consumption occurred on any bus. The trends in this small variation were mixed - the MGSD lead to higher fuel consumption in four buses and lower fuel consumption in two buses. The bus-to-bus variability was much greater than the fuel effect. Fuel consumption of no. 2 diesel fuel differed by as much as $23 \%$ between catalyst equipped buses and $16 \%$ between buses without catalysts.

\section{CONCLUSIONS}

- The use of Mossgas synthetic diesel fuel and the use of rebuilt engines and catalysts according to the EPA Urban Bus Retrofit/Rebuild Program both show promise for reducing emissions from older transit buses using Detroit Diesel 6V92 engines.

- The Mossgas synthetic diesel fuel had properties conducive to low emissions, including no detectable sulfur, and an aromatic content of about $10 \%$ by volume. The Mossgas synthetic diesel also had excellent cold flow properties.

- Drivers could not detect a performance difference between buses operating on the Mossgas synthetic diesel and the Federal no. 2 diesel fuel over the CBD driving cycle.

- Use of Mossgas synthetic diesel in place of Federal no. 2 diesel in the test buses led to lower levels of all four regulated emissions measured. For the buses with rebuilt engines and oxidation catalytic converters, oxides of nitrogen were reduced by an average of $8 \%$, particulate matter was reduced by an average of $31 \%$, carbon monoxide was reduced by an average of $35 \%$, and total hydrocarbon emissions were reduced by an average of $49 \%$.

- The variation of fuel consumption with test fuel was less than $3 \%$ and was much smaller than the bus-tobus fuel consumption variation.
- More precisely defined heavy-duty vehicle chassis dynamometer testing protocols are needed to avoid measurement differences between facilities due to catalyst warm-up.

\section{ACKNOWLEDGMENTS}

The authors would like to extend special acknowledgment to Mossgas (Pty) Ltd for their participation and expert contribution to this study. We would also like to acknowledge the support and hard work of all of those involved in the transit bus evaluation project, the emissions. measurement effort, and the procurement and analysis of Mossgas synthetic diesel fuel: Mike Frailey, NREL; Kevin Chandler, Battelle; Karen Kohl, Southwest Research Institute; the Port Authority of Allegheny County; Byron Rapp, James Kopasko, and Wenwei Xei, West Virginia University; and the West Virginia University laboratory staff.

\section{REFERENCES}

1. Fischer, F. and Tropsch, $H$., "Verfahren zur Gewinnung mehrgliedriger Paraffinkohlenwasserstoffe aus Kohlenoxyden und Wasserstoff auf katalytischem Wege," DRP 484337 (German patent), 1926.

2. "The Slurry Phase Distillate Process, High Quality Diesel for a Cleaner World," Sasol Brochure, Sasol Synfuels International.

3. van Wechem, H.M.H. and Senden, M.M.G., "Conversion of natural gas to transportation fuels $v$... the Shell Middle Distillate Synthesis Process," Natural Gas Conversion Symposium, Sydney, 1993.

4. Eilers, J. Posthuma, S.A. and Sie, S.T., "The Shell Middle Distillate Synthesis Process (SMDS)," Catalysis Letters, 7, 1990.

5. "Indirect Coal Liquefaction," at DOE Fossil Energy web site http://www.fe.doe.gov/coal_power.

6. Basta, N., "Gas-to-Liquid Synfuel Technology Steps Closer to Commercialization," at Hydrocarbon Online web site http://news.hydrocarbononline.com/featurearticles, 1997.

7. Gray, D. and Tomlinson, G., "Gas-to-Liquids: The Opportunities, Technologies and Issues," Proceedings on Gas-to-Liquids Processing- Bringing Clean Fuels to Market, Intertech Conferences, 1998.

8. Norton, P., Vertin, K., Bailey, B., Clark, N.N., Lyons, D.W., Goguen, S., and Eberhardt, J., "Emissions from Trucks using Fischer-Tropsch Diesel Fuel," SAE Paper. 982526, 1998

9. Schaberg, P., Myburgh, I.S., Botha, J.J., Roets, P.N., Viljoen, C.L., Dancuart, L.P. and Starr, M.E., "Diesel Exhaust Emissions Using Sasol Slurry Phase Distillate Fuels," SAE Paper 972898, 1997.

10. Leet, J., "Potential Application of Fischer-Tropsch Fuels," Proceedings on Gas-to-Liquids Processin Bringing Clean Fuels to Market, Intertech Conferences, 1998.

11. Peckham, J., "Reformulated Diesel Tests," Hart's Diesel Fuel News, Vol. 2, No. 10, May 21, 1998. 
12. Martin, B., Aakko, P., Beckman, D., Giacomo, N.D., and Giavazzi, F., "Influence of Future Fuel Formulations on Diesel Engine Emissions- A Joint European Study," SAE Paper 972966, 1997.

13. Chandler, K., Norton, P. and Clark, N., "Alternative Fuel Truck Evaluation Project- Design and Preliminary Results," SAE Paper 981392, 1998.

14. Mossgas Test Report, Low Aromatic Distillate, Tank 51TK127B, January 1998, Letter Report to West Virginia University, July 22, 1998.

15. Kohl, Karen B., Southwest Research Institute, SwRI Project Number 08-2326-060, Final Letter Report to NREL, February 241999.

16. Analysts, Inc., Record Reference Number 478240 , Final Letter Report to West Virginia University, February 11, 1999.

17. Bata, R., Clark, N., Gautam, M., Howell, A., Long, T. Loth, J., Lyons, D., Palmer, M., Rapp, B., Smith, J., and Wang, W., "The First Transportable Heavy Duty Vehicle Emissions Testing Laboratory," SAE Paper 912668, 1991.

18. Bata, R., Clark, N., Lyons, D., Long, T., Howell, A., Loth, J., Palmer, M., Rapp, B., and Wang, W., "A Transportable Heavy Duty Vehicle Emissions Testing Laboratory: A New Dimension in Vehicle Testing," ASME Paper 92-ICE-21, 1992.

19. Clark. N. N., Gautam, M., Bata, R-M., and Lyons, D. W., "Design and Operation of a New Transportable Laboratory for Emissions Testing of Heavy Duty Trucks and Buses," International Journal of Vehicle Design: Heavy Vehicle Systems, Vol. 2, Nos. 3/4, pp. 285-299. 1995.

20. Clark. N. N., Lyons, D. W.. Wang, W., Rapp, B. L. Gautam, M., Wang, W., Norton, P., White, C., and Chandler, K., "Emissions from Trucks and Buses Powered by Cummins L-10 Natural Gas Engines," SAE Paper 981393, 1998.

21. Clark, N. N., Gautam M., Lyons, D. W., Bata, R. M., Wang, W., Norton, P., and Chandler, K. "Natural Gas and Diesel Transit Bus Emissions: Review and Recent Data," SAE Paper 973203, 1997.

22. Chandler, K., Malcosky, N., Motta, R., Norton, P., Kelly, K., Schumacher, L. and Lyons, D. W., "Alternative Fuel Transit Bus Evaluation Program Results," SAE Paper 961082, 1996.

23. Clark. N. N., Gadapati, C. J., Kelly, K., White, C. L., Lyons, D. W.. Wang, W., Gautam, M. and Bata, R., "Comparative Emissions from Natural Gas and Diesel Buses," SAE Paper 952746,1995.

24. Wang, W., Gautam, M., Sun, X., Bata, R-, Clark, N., Palmer, M. and Lyons, D. W., "Emissions Comparisons of Twenty-Six Heavy Duty Vehicles Operated on Conventional and Alternative Fuels," SAE Paper 932952, 1993.
25. Bata, R, Lyons, D. W., Clark, N., Gautam, G. and Wang, W. , "Vehicle Performance and Exhaust Gas Emissions of In-use Methanol Fueled Transit Buses," Eleventh International Symposium on Alcohol Fuels, April 1996, Sun City, South Africa, Vol. 3, pp. 809820,1996.

26. Messer, J.T., Clark, N.N., and Lyons, D.W., "Measurement Delays and Modal Analysis for a Heavy-Duty Transportable Emissions Testing Laboratory," SAE Paper 950218, 1995.

27. Clark, N.N., Lyons, D.W., Rapp, B.L., Gautam, M., Wang, W., Norton, P., White, C., and Chandler, K., "Emissions from Trucks and Buses Powered by Cummins L-10 Natural Gas Engines," SAE Paper $981393,1998$.

28. Clark, N.N., Gautam, M., Lyons, D.W., Bata, R.M., Wang, W., Norton, P., and Chandler, K., "Natural Gas and Diesel Transit Bus Emissions: Review and Recent Data," SAE Paper 973203, 1997.

29. Wang, W., Clark, N.N., Lyons, D.W., Yang, R., Gautam, M., Bata, R., and Loth, J., "Emissions Comparisons from Alternative Fuel Buses and Diesel Buses with a Chassis Dynamometer Testing Facility", Environmental Science \& Technology, Vol. 31, No. 11, 1997.

\section{DEFINITIONS, ACRONYMS, ABBREVIATIONS}

CBD - Central Business District (driving cycle)

CO - Carbon Monoxide

COD - Conversion of Olefins to Distillate

DDC - Detroit Diesel Corporation

DOE - U.S. Department of Energy

EPA - Environmental Protection Agency

EPACT - Energy Policy Act of 1992

FBP - Final Boiling Point

FIA - Fluorescent Indicator Adsorption

F-T diesel - Fischer-Tropsch diesel

FTP - Federal Test Procedure

GTL - Gas-to-liquids

HC - Hydrocarbons

HFRR - High Frequency Reciprocating Rig

IBP - Initial Boiling Point

MGSD - Mossgas synthetic diesel

$\mathrm{NO}_{x}$ - Oxides of Nitrogen

NREL - National Renewable Energy Laboratory

PM - Particulate Matter

ppm - parts per million

SFC - Supercritical Fluid Chromatography

SLBOCLE - Scuffing Load Ball On Cylinder Lubricity Evaluator

THC - Total Hydrocarbons

WVU - West Virginia University 